Available online at GSC Online Press Directory

GSC Biological and Pharmaceutical Sciences

e-ISSN: 2581-3250, CODEN (USA): GBPSC2

Journal homepage: https://www.gsconlinepress.com/journals/gscbps

(REVIEW ARTICLE)

\title{
Association of Helicobacter pylori infection and vitamin B12 deficiency
}

\author{
Al-aajem Burooj M. Razooqi * \\ Department of Microbiology, College of Medicine, Diyala University, Diyala, Iraq.
}

Publication history: Received on 29 July 2019; revised on 18 August 2019; accepted on 25 November 2019

Article DOI: https://doi.org/10.30574/gscbps.2019.9.2.0143

\begin{abstract}
H. pylori infection is strongly related with chronic gastritis of the stomach, which causes impairment in gastric acid and secretion of pepsin, and linked to male absorption of food-vitamin B12. The most important virulence genes accompanying stomach and intestine disease are (cag A and vac A). Aim of the study: To evaluate the rate of gastric ulcer infection with $H$. pylori and its detect CagA gene in H.pylori isolated from gastritis. Materials and Methods: A total of 200 biopsy patients aged from $(10-\geq 60)$ years were collected from Baqubah teaching hospitals. They were suffering from gastric upset and attended to endoscopic unit of department of medicine. Questioners including, sex, age, smoking, presence of cancer, and biopsies of gastric tissue were collected from the corpus or the ant rum or corpus and ant rum of the patient's stomach. Three biopsies were taken from each patient. Histopathologic study, gram staining, and rapid urease test working for each patients. Serology Test Serum Enzyme-Linked Immunosorbent Assay Testing (ELISA).
\end{abstract}

Keywords: Gastric ulcer; H. pylori; Cag A gene; Stomach ulcer; Duodenal ulcer

\section{Introduction}

Helicobacter pylori (H. pylori) affects nearly half of the world's population, thus is one of the most frequent and persistent bacterial infections (1). H. pylori is associated with peptic ulcer, gastric ulcers, mucosa-associated lymphoid tissue, and gastric cancer. It infects the stomach during childhood. In developing countries children are very commonly infected. $H$. pylori may be passed from person to person through direct contact with vomit, saliva, or fecal matter. Risk factors for H. pylori infection are related to: living in crowded conditions area, without a reliable supply of clean water, living in a developing country, or with someone who has a H. pylori infection. (2).The cases Vitamin $\mathrm{B}_{12}$ deficiency is attributed to malnutrition. H. pylori infection plays an important role in the development of atrophic gastritis and related malabsorption. It is suggested that there may be a relationship between $H$. pylori infection and vitamin $\mathrm{B}_{12}$ deficiency (3). A study of H. pylori IgG Antibodies in Iraqi Uremic patients is designed to evaluate the effect of blood urea and serum creatinine level, on gastric enzymes and H. pylori infection in patients with end stage renal failure before and after kidney transplantation, also to detect the association between the Human Leukocyte antigens (HLA) class I , II antigens with H.pylori infection (4). During the period October 2006 to July 2007 a study was done by WHO which involve Isolation and identification of $H$. pylori from drinking water in Basra governorate, Iraq. 198 samples of drinking water, from 22 districts of Basra governorate were collected. Only 14 isolates were Helicobacter spp., of which 10 were $H$. pylori. These isolates, were tested for antibiotic susceptibility as well as ability to tolerate chlorine at $0.5 \mathrm{mg} / \mathrm{L}$. They reported the occurrence of $H$. pylori in treated drinking water (5). Another study was done in Al-Sadar Teching Hospital in Basrah in 2018 which involved 100 samples was taken from patients with peptic ulcer. The result revealed that (36\%) H. pylori infected patients had normal vitamin B12 level and (64\%) were Vitamin B12 deficiency in (86\%) H. pylori infected patients (6). Aim of study: - study the relationship between H. pylori and vitamin B12 deficiency. H. pylori is Gramnegative microaerophilic bacterial (7), appear spiral-shaped. The organism has 2 to 6 unipolar, sheathed flagella which often carry a distinctive bulb at the end. The flagella confer motility and allow rapid movement in viscous solutions such as the mucus layer toward the more neutral $\mathrm{pH}$ of the gastric mucosa. H. pylori are urease positive which thought to

\footnotetext{
${ }^{*}$ Corresponding author

E-mail address: m.rburooj@yahoo.com
} 
allow short-term survival in the highly acidic gastric lumen. The flagella confer motility and allow rapid movement in viscous solutions such as the mucus layer overlying the gastric epithelial cells $(8,9,10)$. The helical shape of $H$. pylori is crucial for bacterial motility and a prerequisite for successful colonization (11). Motility has been shown to be essential for successful in vivo colonization by $H$. pylori and is provided by its sheathed flagella. In this respect, proposed that bacterial chemo sensing and motility promoted very rapid $H$. pylori colonization of injury sites, thereby contributing toward sustained gastric damage, by slowing down gastric repair (12). Chemotaxis allows a bacterium to control its swimming behavior in response to chemical signals.(13). Adherence A study was done in 2014 shows that the blood groups antigen-binding adhesion (BabA), an outer membrane protein occur commonly, driven by mutation and recombination, resulting in a complete loss of protein expression or in gradual changes in binding properties (14). Persistence A successful establishment of infection in such an acidic stomach is active intracellular urease, a major constituent of the total bacterial proteins output of $H$. pylori. This enzyme responsible for ammonium assimilation were involved in regulating either the hydrolysis of urea inside the cell of stomach, or the extent to which this ammonium was extruded versus assimilated, supporting the association between the assimilation of $\mathrm{NH} 4$ and the primary acid resistance mechanism in H. pylori (15). H. pylori persistence has been demonstrated to be favored by the activity of (gGT), which has been demonstrated to impair T-cell proliferation (16). Cag A H. pylori strains are more virulent strain and are associated with gastric carcinoma, cagA, is injected by the bacterium into gastric epithelial cells and subsequently undergoes tyrosine phosphorylation. The phosphorylated cagA specifically binds SHP-2 phosphatase, activates the phosphatase activity, and induces morphological transformation of cells (17). The epidemiology of $H$. pylori has been changing over the last decades, with a decline of the prevalence of the infection in most countries. The changing epidemiology of the bacterium has been associated with decline in peptic ulcer disease and gastric cancer (18) and may have an impact on the changing epidemiology of other diseases, such as gastro esophageal reflux disease, and asthma $(19,20)$. The clinical features of $H$. pylori range from asymptomatic gastritis to gastrointestinal malignancy $(21,22)$. Vitamin B12 is an essential cofactor that is integral to methylation processes important in reactions related to DNA and cell metabolism, deficiency may lead to disruption of DNA and cell metabolism and thus have serious clinical consequences (23). Vitamin B12 cannot be synthesized in the body so must be obtained from the diet. The main dietary sources of B12 are dairy products, meat and eggs. The acidic environment of the stomach enables the release of B12 that is bound to food (24). The free B12 is rapidly bound by intrinsic factor (IF), a muco-polysaccharide secreted by gastric parietal cells that line the stomach. The binding of B12 to IF occurs in the duodenum causing the formation of the IF-B12 complex (25). This complex is resistant to digestion by stomach juices. Reaching the terminal ileum, it binds to and is absorbed by the intestinal microvilli $(26,27)$. These functions take place in fatty acid, amino acid and nucleic acid metabolic pathways. The deficiency of vitamin B12 is clinically manifested in the blood and nervous system where the cobalamin plays a key role in cell replication and in fatty acid metabolism (28). Vitamin B12 (Vit B12) deficiency is a common condition, which can be manifested with non-specific clinical features or with neurological or haematological bnormalities in severe cases. In systemic sclerosis (SSc) gastrointestinal involvement, nutritional status may lead to Vit B12 deficiency (29). Deficiency of vitamin B12 is cause of megaloblastic anemia. It is a reversible cause of bone marrow failure (30). Chronic gastritis owing to H. pylori infection (Hp-I) can lead to malabsorption of Vitamins B12 and folate, which results in failure of methylation by 5-methyl-tetrahydrofolic acid and accumulation of Hcy (30).

The studies showed that age group (40-49) and (50-59) was the most age group of people with bacteria H. pylori as the percentage (29.10\%). From 200 biopsy samples.

\section{Conclusion}

H. pylori infection is strongly related with chronic gastritis of the stomach. The presence of this genes related with chronic gastritis and stomach ulcer.

\section{Compliance with ethical standards}

\section{Acknowledgments}

I would like to thank the cadre of the educational labs at Baquba Teaching Hospital and the specialized surgeons to help complete this useful scientific study.

\section{Disclosure of conflict of interest}

There is no conflict of interest with any governmental institutions. 


\section{References}

[1] Goh KL, Chan WK, Shiota S and Yamaoka Y. (2011). Epidemiology of Helicobacter pylori Infection and Public Health Implications. Helicobacter. 16(0-1), 1-9.

[2] Ieni A, Barresi V, Rigoli L, Fedele F, Tuccari G and Caruso RA. (2016). Morphological and Cellular Features of Innate Immune Reaction in Helicobacter pylori Gastritis: A Brief Review. International Journal of Molecular Sciences. 17(1), 109.

[3] Ravi K, Jacob J and David MT. (2017). Helicobacter pylori infection and vitamin B-12 deficiency- A cross sectional study. Asian Journal of Medical Sciences, 8(4).

[4] Al-Maliki SAK, AL-Hadithi HS and Khatab OS. (2011). Helicobacter pylori IgG Antibodies in Iraqi Uremic patients in association with Pepsinogens and Human Leukocyte Antigens class I \& II. College of Medicine -Baghdad University

[5] Al-Sulami AA, Al-Taee AMR and Juma'a MG. (2010). Isolation and identification of Helicobacter pylori from drinking water in Basra governorate, Iraq. Eastern Mediterranean Health Journal, 16(9), 220-5.

[6] Kadhim G, Shikh M, Omar H and Ismail A. (2018).Vitamin B12 Deficiency in Helicobacter pylori Infected Patients. Open Access Library Journal. 5(3), 4. 10.4236.

[7] Hirukawa S, Sagara H, Kaneto S, Kondo T, Kiga K, Sanada T, Kiyono H and Mimuro H. (2018). Characterization of morphological conversions of Helicobacter pylori under anaerobic conditions.

[8] Rudnicka K, Graczykowski M, Tenderenda M and Chmiela M. (2014). Helicobacter pylori morphological forms and their potential role in the transmission of infection. Postepy Hig Med Dosw. 4(68), 219-29.

[9] O’Toole PW, Lane MC and Porwollik S. (2000). Helicobacter pylori motility. Microbes Infect. 2, 1207-14.

[10] Marais A, Mendz GL, Hazell SL and Megraud F. (1999). Metabolism and genetics of Helicobacter pylori: the genome era. MicrobiolMol Biol Rev, 63, 642-74.

[11] An DR, Kim HS and Kim J. (2015). Structure of Csd3 from Helicobacter pylori, a cell shape-determining metallopeptidase. Acta Crystallogr D Biol Crystallogr, 71, 675-86.

[12] Aihara E, Closson C, Matthis AL, Schumacher MA, Engevik AC, Zavros Y, Ottemann KM and Montrose MH. (2014). Motility and chemotaxis mediate the preferential colonization of gastric injury sites by Helicobacter pylori. PLoS Pathog, 10 (7), 1-17.

[13] Sigal M, Rothenberg ME and Logan CY. (2015). Helicobacter pylori activates and expands Lgr5 stem cells through direct colonization of the gastric glands. Gastroenterology, 148 (7), 1392-404.

[14] Nell S, Kennemann L, Schwarz S, Josenhans C and Suerbaum S. (2014). Dynamics of Lewis b binding and sequence variation of the babA adhesin gene during chronic Helicobacter pylori infection in humans. MBio, 5(6), 2281-14.

[15] Tenguria S, Ansari SA, Khan N, Ranjan A, Devi S, Tegtmeyer N, Lind J, Backert S and Ahmed N. (2014). Helicobacter pylori cell translocating kinase (CtkA/JHP0940) is pro-apoptotic in mouse macrophages and acts as autophosphorylating tyrosine kinase. Int J Med Microbiol, 304(8), 1066-76.

[16] Wustner S, Mejias-Luque R, Koch MF, Rath E, Vieth M, Sieber SA, Haller D and Gerhard M. (2015).Helicobacter pylori gamma-glutamyltranspeptidase impairs T-lymphocyte function by compromising metabolic adaption through inhibition of cMyc and IRF4 expression. Cell Microbiol, 17(1), 51-61.

[17] Higashi H, Tsutsumi R, Fujita A, Yamazaki S, Asaka M, Azuma T and Hatakeyama M. (2002). Biological activity of the Helicobacter pylori virulence factor CagA is determined by variation in the tyrosine phosphorylation sites, 99 (22), 14428-3.

[18] Fuccio L, Eusebi LH and Bazzoli F. (2010). Gastric cancer, Helicobacter pylori infection and other risk factors.WJGO, 2(9), 342-7.

[19] Sonnenberg A. (2013). Historic changes of Helicobacter pylori-associated diseases. A P T, 38(4), 329-42.

[20] Leonardo HE, Rocco MZ and Franco B. (2014). Epidemiology of Helicobacter pylori in fection. Helicobacter, 19(s1), 1-180.

[21] American College of Physicians. (2003). MKSAP 17: medical knowledge self-assessment program. Philadelphia: American College of Physicians; 2015. 
[22] Bhat, Sriram. SRB's Manual of Surgery. London: Jaypee Brothers Medical Publisher; 2013.364. ISBN 9789350259443.

[23] Rimbara E, Sasatsu M and Graham DY. (2013). PCR detection of Helicobacter pylori in clinical samples. Methods Mol Biol. 943, 279-87.

[24] Green R. (2013). Physiology, dietary sources, and requirements. In: Encyclopedia of human nutrition. Academic Press, 4, 351-6.

[25] Robert C and Brown DL. (2003). Vitamin B12 deficiency. Am Fam Phy, 67(5), 979-86.

[26] Butler CC, Vidall-Alaball J, Cannings R et al. (2006). Oral vitamin B12 versus intramuscular vitamin B12 for vitamin B12 deficiency: a systematic review of randomized control trials. Fam. Prac, 23(3), 279-85.

[27] Hin H, Clarke R, Sherliker P et al. (2006). Clinical relevance of low serum vitamin B12 concentrations in older people: the Banbury B12 study. Age Aging, 35(4), 416- 22.

[28] Kozyraki R and Cases 0. (2013). Vitamin B12 absorption: Mammalian physiology and acquired and inherited disorders. Biochimie, 95(5), 1002-7.

[29] Rizzo l, Laganà AS, Rapisarda AMC , La Ferrera GMG, Buscema M, Rossetti P, Nigro A, Muscia V, Valenti G, Sapia F, Sarpietro G, Zigarelli M and Vitale SG. (2016). Vitamin B12 among Vegetarians: Status, Assessment and Supplementation. Nutrients, 8(12), 767.

[30] Kilic DT, Sari A, Armagan B, Erden A, Kilic L, Kilinckaya M, Turhan T, Akdogan A and Karaahmetoglu S. (2017). FRI0397 Evaluation of vitamin b12 deficiency and associated factors in patients with systemic sclerosis. BMJ. $76(2)$.

\section{How to cite this article}

Al-aajem Burooj M. Razooqi. (2019). Association of Helicobacter pylori infection and vitamin B12 deficiency. GSC Biological and Pharmaceutical Sciences, 9(2), 143-146. 